\title{
Digital calcinosis cutis in a neonate after thromboembolism
}

\begin{abstract}
Dystrophic calcinosis cutis is an uncommon condition characterized by the deposition of insoluble calcium salts in previously damaged tissue triggered, for example, after hypovascularity or tissue hypoxia, with normal serum calcium and phosphorus levels. We herein report a dystrophic calcification of the fingertips in a neonate secondary to ischemia caused by thromboembolism after catheter manipulation.
\end{abstract}

Keywords: calcinosis cutis, neonate, thromboembolism, isquemia, catheter

\author{
Volume 3 Issue 5 - 2019

\section{Laura Vergara-de-la-Campa, Beatriz Moreno- Torres, Cristina Pérez- Hortet, Ana Isabel \\ Sánchez-Moya} \\ Dermatology Department, Hospital Complex of Toledo, Spain
}
Correspondence: Laura Vergara de la Campa, Dermatology Department, Hospital Complex of Toledo, Ctra Cobisa, Postal address: 4507।, Toledo, Spain, Tel +34 638186844,
Email laura.vergara.de.la.campa@gmail.com

Received: October 01, 2019 | Published: October 24, 2019

\section{Introduction}

Dystrophic calcinosis cutis is an uncommon condition characterized by the deposition of insoluble calcium salts after local tissue damage or abnormalities such as alterations in the collagen, elastin or subcutaneous fat, with normal serum calcium and phosphorus levels. ${ }^{1,2}$ Although typically seen in connective tissue diseases, inherited disorders or cutaneous neoplasms, dystrophic calcification has been reported following local tissue damage after fractures, burn scars, neonatal heel pricks, or local trauma. ${ }^{1,3}$ Tissue damage, hypoxia, or hypovascularization induces necrotic cells to release phosphate-binding proteins taking up phosphate thereby resulting in calcification. ${ }^{2}$ We report a case of dystrophic calcification of the fingertips in a neonate secondary to ischemia caused by thromboembolism after catheter manipulation in the axillar area, mechanism not reported in previous literature.

\section{Case report}

A four-month-old female was referred to the Dermatology department for the evaluation of asymptomatic white lesions of stony consistency on the fingertip of the fourth and fifth finger of her right hand, dermoscopy showed round homogeneous white images with hyperkeratotic collar (Figure 1). The patient was born preterm at 26 weeks gestation, presenting with hyaline membrane disease, bronchopulmonary dysplasia and mild pulmonary hypertension. During admission, she developed ischemia of digital arteries in the right hand, due to thromboembolism secondary to the manipulation of an epicutaneous catheter in the right axillary artery. The patient required amputation of the distal phalanx of the second finger as well as distal and half of the middle phalanx of the third finger, two months later, lesions on the fingertips started to appear. The results of the routine complementary tests were normal except for elevated alkaline phosphatase values (2492 IU/L) without other alterations of phosphocalcic metabolism. These values normalized after one month, meeting the diagnostic criteria of benign transient childhood hyperphosphatemia. ${ }^{4}$ An X-ray of the right hand was also performed, showing hyperdense round images on the palm side of the 4th and 5th fingers suggesting of calcifications (Figure 2 amputated phalanges (Figure 20). Under local anesthesia, because the lesions were predominantly detached, curettage was performed on the remaining areas. Histology showed granules and globules of basophilic calcified material (Figure $3 \star$ ) and foreign body giant cell reaction in dermis (Figure $3 \mathbf{\Delta}$ ).

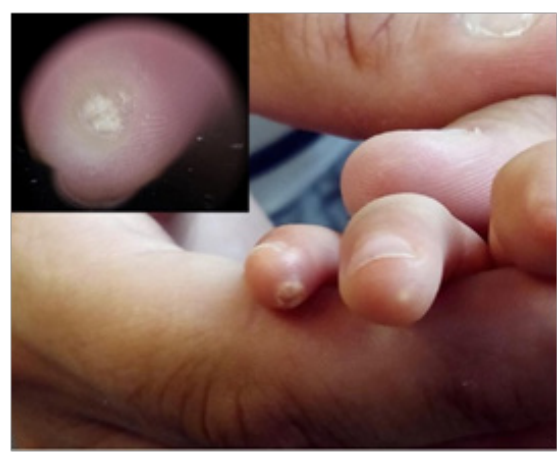

Figure I Clinical image, White hard lesions on the fingertips of the 4th and 5 th right hand fingers, dermoscopy revealed rounded homogeneous whitish images with hyperkeratotic collar.

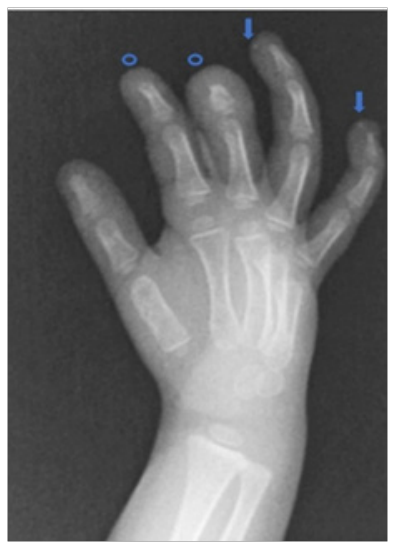

Figure 2 Right hand radiography. Hyperdense round images are observed on the palmar side of the 4 th and 5 th fingers suggesting of calcifications ( 1 ).Also, amputation of the distal phalanx of the 2 nd finger as well as distal and half of the middle phalanx of the 3 rd finger of the right hand $(\mathbf{0})$. 


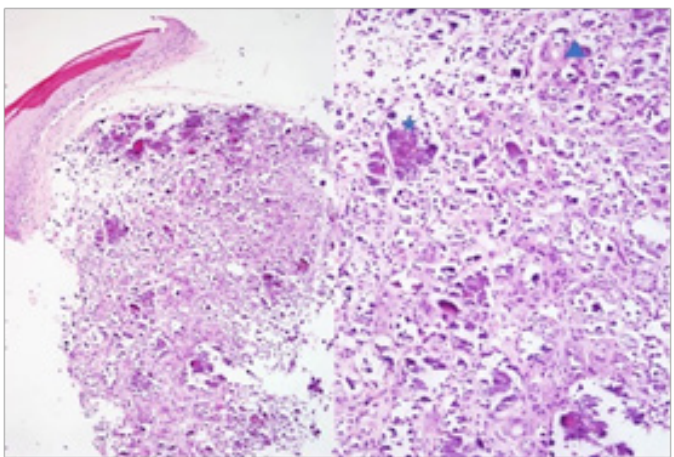

Figure 3 Calcifications are observed $(\boldsymbol{\star})$ in superficial papillary and deeper reticular dermis surrounded by foreign body giant cell reaction $(\boldsymbol{\Delta})$.

\section{Discussion and conclusions}

Dystrophic calcinosis cutis is an infrequent affectation in the neonatal period with a small number of published cases. Being the pathogenesis of calcinosis cutis multifactorial, dystrophic calcinosis cutis is the most frequent form of skin calcinosis and arises as a result of the deposition of insoluble calcium salts in previously damaged tissue, with normal serum calcium and phosphorus levels. ${ }^{1,2}$ Tissue damage due to hypovascularity or tissue hypoxia promotes increased intracellular calcium entry, with consequent tissue mineralization. ${ }^{2}$ There are also published cases of iatrogenic calcinosis cutis in newborns after repeated attempts to insert peripheral lines, extravasation of substances containing calcium or phosphorus triggering local tissue damage together with temporary elevations of serum and/or tissue calcium levels..$^{5-7}$ In the case of our patient, due to clinical history and given the triggering ischemic event and no iatrogenic deposition of calcium or phosphorus material in the affected area, the patient was diagnosed with dystrophic skin calcinosis. We have not found any other case due to ischemia secondary to a thromboembolic event after manipulation of an epicutaneous catheter. In addition, the cutaneous clinic and dermoscopic images are highly characteristic. We want to spread this knowledge to primary care physicians and pediatricians for an early diagnosis

\section{Acknowledgements}

None.

\section{Conflicts of interest}

The authors declare no conflicts of interest.

\section{References}

1. Reiter N, El-Shabrawi L, Leinweber B, et al. Calcinosis cutis: part I. Diagnostic pathway. J Am Acad Dermatol. 20111;65(1):1-12;13-4.

2. Jiménez-Gallo D, Ossorio-García L, Linares-Barrios M. Calcinosis cutis y calcifilaxis. Actas Dermo-Sifiliográficas. 2015 Dec 1;106(10):785-794.

3. Hattori M, Shimizu A, Ishikawa O. Dystrophic calcinosis cutis of the auricles after injury in Down's syndrome. J Dermatol. 2018;45(11):e314 e316.

4. Kraut JR, Metrick M, Maxwell NR, et al. Isoenzyme studies in transient hyperphosphatasemia of infancy. Ten new cases and a review of the literature. Am J Dis Child. 1985;139(7):736-740.

5. Ching DLH, Wong KY, Milroy C. Iatrogenic calcinosis cutis following a neonatal extravasation injury. Br J Hosp Med Lond Eng. 2014;75(5):295.

6. Cherian EV, Shenoy KV, Daniel J. Iatrogenic calcinosis cutis in a neonate. BMJ Case Rep. 2013; pii: bcr2012007793.

7. Arora A, Agarwal A, Kumar S, et al. Iatrogenic calcinosis cutis--a rare differential diagnosis of soft-tissue infection in a neonate: a case report. $J$ Orthop Surg Hong Kong. 2005;13(2):195-198. 